\title{
Entrevista $^{1}$
}

\author{
Orly Zucatto Mantovani de Assis
}

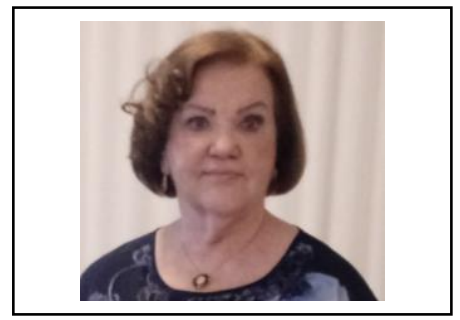

Orly Zucatto Mantovani de Assis é pedagoga e iniciou sua carreira como professora do ensino fundamental no município de Amparo-SP. Durante esse período, interessou-se em compreender o que ocorria com os alunos quando estes demonstravam não reter aquilo que lhes era transmitido, no que se refere à matemática elementar. Passou então a se dedicar ao estudo e aprofundamento sobre o desenvolvimento e a aprendizagem, numa perspectiva piagetiana, tendo concluído seu doutoramento em 1976, pela UNICAMP. Sua investigação provou que um processo, denominado pela pesquisadora de Processo de Solicitação do Meio e caracterizado por mudanças no ambiente físico da sala, na estrutura diária das atividades, na conduta do professor, na maneira como as relações interpessoais se processam e no tipo de atividade e material oferecido ao aluno, favorece o desenvolvimento da criança em seus aspectos cognitivo, afetivo, social e psicomotor. Esse processo denominado de PROEPRE- Programa de Educação Pré-Escolar-inicialmente, e depois Programa de Educação Infantil e Ensino Fundamental, embasado na teoria piagetiana foi implantado em mais de vinte Secretarias Estaduais de Educação e Secretarias de Educação Municipais de inúmeras cidades do Distrito Federal, São Paulo, Minas Gerais, Pará, Mato Grosso do Sul, Mato Grosso, Piauí. De 1992 em diante, os cursos para formação de professores do PROEPRE passaram a ser oferecidos anualmente pela Escola de Extensão da UNICAMP, com mais de 140 turmas até a atualidade. Desde 1983, a professora Orly coordena o Laboratório de Psicologia Genética da Faculdade de Educação da UNICAMP e grupo de pesquisa do $\mathrm{CNPq}$, tendo orientado mais de 130 trabalhos entre teses, dissertações, trabalhos de conclusão de curso e de iniciação científica. Foi em 1994, por ocasião do III Simpósio Internacional de Epistemologia Genética, realizado em Águas de Lindóia-SP e organizado pela professora Orly, que Juan Delval esteve no Brasil pela primeira vez, trazendo, naquele momento, dados inusitados sobre suas pesquisas a respeito do conhecimento social. A professora Orly está, atualmente, atuando como docente do Programa de Pós-Graduação em Educação da UNICAMP e permanece coordenando o LPG e os cursos de formação de professores do PROEPRE.

\footnotetext{
${ }^{1}$ Entrevista concedida a Érica de Cassia Gonçalves na cidade de Campinas-SP. 
E: Os estudos que a senhora orientou que tiveram como tema o conhecimento social foram pioneiros em nosso país? Como foi esse início de pesquisas? Qual foi a motivação para estudar esse campo de conhecimento? Orly: Penso que sim. Se eu me lembro bem, quando o Prof, Delval esteve pela primeira vez no Brasil e realizou alguns seminários aqui, no LPG (Laboratório de Psicologia Genética/FE/UNICAMP), algumas pósgraduandas que faziam parte de nosso grupo de pesquisa se interessaram por esse tema, dentre elas, a Eliane, a Roberta, a Valéria, a Larissa ${ }^{2}$.

\section{E: Então, Orly, o início da pesquisa foi depois que Juan Delval esteve aqui no Brasil?}

Orly: Sim, depois que Delval esteve pela primeira vez entre nós, participando do III Simpósio Internacional de Epistemologia Genética e dos Encontros do PROEPRE de Águas de Lindóia/SP e ministrando palestras e seminários, promovidos pelo LPG, aqui na Faculdade de Educação. A motivação foram os trabalhos que nós tomamos conhecimento que o Delval e a Ileana Enesco nos trouxeram. Eles não só trouxeram pesquisas como também várias publicações sobre o Conhecimento Social que passaram a compor o acervo do LPG e serviram como referências iniciais para nossos orientandos formularem seus problemas de pesquisa.

\section{E: Como a senhora vê a evolução das pesquisas sobre o Conhecimento Social aqui no Brasil?}

Orly: Olha, eu tenho ideia dessas pesquisas realizadas no LPG e mais ou menos as da Eliane Saravali, lá na UNESP. Então, a minha hipótese vai abranger apenas Campinas-SP e Marília-SP. Então, eu acho o seguinte: considerando o tempo em que essas pesquisas foram realizadas e também a

\footnotetext{
${ }^{2} \mathrm{~A}$ esse respeito, vale dizer que as pesquisas do Laboratório de Psicologia Genética, orientadas pela professora Orly, foram precursoras dos trabalhos sobre o conhecimento social no Brasil. Grande parte destes trabalhos estão referenciados ao final desta entrevista.
} 
época que a teoria piagetiana começou a ser estudada no Brasil, eu acho que até houve uma evolução significativa. Porque, juntando os trabalhos que a Eliane tem orientado na UNESP de Marília com estes 21 concluídos sob minha orientação, considerando ainda as dificuldades de realização das pesquisas que utilizam o método clínico crítico piagetiano, eu acho que é um número relativamente bom. Eu acho que houve uma expansão grande, considerando o tempo também (de 94/96 para cá).

$E$ : Muitos temas pertinentes ao conhecimento social foram alvo de estudos. A senhora acredita que ainda há espaço para novas pesquisas? $O$ que ainda necessitaria ser explorado?

Orly: Realmente há!

\section{E: A política, seria um conhecimento social?}

Orly: Sim, a ideia que se faz da política brasileira, da democracia. Não podemos esquecer dos trabalhos da Marianela Denegri, sobre as ideias de consumo e educação econômica. Um outro tema que está sendo pesquisado agora, por Eliane Cleonice Alves Precoma, em seu pós doc, supervisionado por mim, trata das Representações de Resiliência e de Redes de Proteção.

E: Orly, a questão da diversidade de gêneros que tem sido muito discutida, poderia ser abordada na perspectiva da construção do conhecimento social?

Orly: Sim, social... diversidade de gênero, mas isso pra mim é também uma questão de inclusão, cuja problemática faz parte do conhecimento social.

\section{E: E este seria um campo a ser explorado também ou não?}

Orly: Sim, também. Resiliência, por exemplo. É um tema importante para ser estudado dentro do campo do conhecimento social. Outra coisa, a violência. Outra questão importante também é a graduação em Educação Social, e estes educadores sociais estão sendo requisitados em obras sociais. Então, por exemplo, aqui na Casa Santana (Centro de Convivência e 
Inclusão Social para a Cidadania de Campinas) eles têm o programa Jovem Aprendiz e, para este programa, foram contratados educadores sociais.

\section{E: Como a senhora avalia as práticas pedagógicas que ocorrem em nossas escolas e que envolvem a construção do conhecimento social?}

Orly: Eu acho que as práticas pedagógicas que têm em vista a construção do conhecimento social, em geral, são práticas que utilizam apenas a transmissão social. Não há, no meu modo de ver, o entendimento de que o conhecimento social é também construído, isto até daria uma boa pesquisa para se fazer, para provar isso, é uma hipótese. Vamos encontrar, na maioria das escolas, um trabalho que não considera o que o aluno pensa sobre o conhecimento social. Existe um livro que se chama "Piaget: o diálogo com a criança e o desenvolvimento do raciocínio" de Maria da Glória Seber. Ela fez uma pesquisa sobre como a criança entende a história do Brasil, por exemplo. Os resultados encontrados por ela mostram a não compreensão dos fatos históricos, devido à maneira como eles são ensinados. Outra coisa que não se leva em consideração ao trabalhar o conhecimento social é o nível de desenvolvimento da criança. Segundo a pesquisa de Seber, ao falar sobre o que sabe a respeito da história do Brasil, crianças do $4^{\circ}$ e $5^{\circ}$ ano misturam acontecimentos, causas e consequências revelando uma total incompreensão, como por exemplo: que D. Pedro I descobriu o Brasil, e Cabral gritou "Independência ou Morte" semelhante ao chamado "Samba do Crioulo Doido". É um samba em que a história do Brasil é toda contada erradamente, incoerentemente, invertida de modo a se fazer rimas. O que as crianças, na verdade, fazem com os conteúdos de história que elas

aprendem? É um verdadeiro samba do crioulo doido! Por exemplo, na letra do samba se diz que a princesa Leopoldina virou estação de trem, isso é compreendido por elas ao pé da letra. Já ouvi uma criança dizer que o Brasil tinha uma coberta em cima e veio Cabral e "descobriu” o Brasil (risos).

E: O Proepre, programa que a senhora criou, propõe ações específicas para o 


\section{trabalho com o conhecimento social. Quais são essas ações?}

Orly: Eu prefiro mencionar os princípios que essas ações devem respeitar. O primeiro é que o conhecimento social é construído. E, inicialmente, quando se trata de trabalhar o conhecimento social, é preciso fazer um levantamento prévio sobre o que a criança já conhece daquilo que a gente quer tratar. Quando a Eliane Saravali, por exemplo, em sua pesquisa sobre os direitos das crianças, perguntou o que é direito, as crianças respondiam: "Direito é assim" (apontando com a mão o lado direito). Eles têm uma ideia e se você não levar em consideração esse conhecimento prévio da criança corre o risco de tudo ser mal compreendido, aí vem aquela história, que a professora perguntou qual era a maior bacia do Brasil, e aí criança respondeu: "A bacia que minha professora toma banho." Porque ele não sabia a que bacia ela estava se referindo, podia até falar que era fluvial, mas ele não sabia o que era fluvial e não sabia o que era bacia. Então, esses mal-entendidos de fato pesam na compreensão. Quanto mais for possível que a criança realize ações sobre os objetos, porque é a partir da ação que o conhecimento social também se constrói e da interação social, é que ela vai ver, por exemplo, se o que ela pensa pode não ser o que o outro pensa, isso poderá levá-la a ideia de uma contradição. Então, os passos seriam realmente os mesmos que são utilizados na construção do conhecimento lógico-matemático e na descoberta do conhecimento físico e invenção do conhecimento lógico matemático. Então é por isso que, quanto mais estes temas corresponderem ao interesse da criança, mais chance têm de ser compreendidos por ela. Por exemplo, existem temas do conhecimento social que satisfaziam mais as crianças, por exemplo: as grandes invenções. Há um texto que se chama "Interesse e Liberdade" de Maria Dolors Busquets que aborda bem essa questão.

Veja, o princípio da ação, Piaget diz que o conhecimento é adquirido por meio da ação sobre o objeto e da interação social, certo? Então, se você respeitar isso, sem esquecer de levar em conta os conhecimentos prévios que a criança tem, porque aí entra o problema da linguagem, você precisa acertar o seu vocabulário com o vocabulário da criança e saber o que ela está 
pensando sobre este tema, porque muitas vezes ela faz a pergunta corretamente, mas ela não sabe nem o que ela está perguntando. Certa vez uma criança pequena perguntou-me, quando estava sentada ao meu lado num carro... estava ventando fiz com que o vidro de sua janela subisse ao acionar um botão, sem que ela percebesse: “- É automático?”, aí eu perguntei o que era automático e ela não sabia o que era. Eles usam a expressão certa, na pergunta certa, mas sem ter uma compreensão do significado daquilo. Então, como o significado do conhecimento social, depende muito da linguagem, é preciso que isto seja considerado, o conhecimento que a criança tem.

A criança terá oportunidades de construir o conhecimento social quando faz inferências, a partir de determinadas informações que poderão ser confirmadas ou não quando interage com adultos ou consulta livros ou mesmo o computador. Em situações como essas a criança adquire o conhecimento a respeito do que está interessada, aprende a pesquisar, a comparar suas ideias com a dos outros pares ou adultos, põe em atividade suas estruturas de pensamento. Enfim, se desenvolve...

\section{Referências}

ARAÚJO, R. M. B. O desenvolvimento do pensamento econômico em crianças: avaliação e intervenção em classes de $3^{\mathrm{a}}$ e $4^{\mathrm{a}}$ série do Ensino Fundamental. 2007. Tese (Doutorado em Educação) - Faculdade de Educação, Universidade Estadual de Campinas, Campinas, 2007.

BAPTISTELLA, E. C. F. A compreensão de um conteúdo de um comercial televisivo na infância. 2001. Dissertação (Mestrado em Educação) - Faculdade de Educação Universidade Estadual de Campinas, Campinas, 2001.

BARROSO, L. M. S. As ideias das crianças e adolescentes sobre seus direitos: um estudo evolutivo à luz da teoria piagetiana. 2000. 327f. Dissertação (Mestrado em Educação) - Faculdade de Educação, Universidade Estadual de Campinas, Campinas, 2000.

BORGES, R. R. A construção da noção de família em crianças pré-escolares. 2001. Dissertação (Mestrado em Educação) Faculdade de Educação, Universidade Estadual de Campinas, Campinas, 2001. 
BRAGA, A. A influência do projeto "A formação do professor e a educação ambiental" no conhecimento, valores, atitudes e crenças nos alunos do ensino fundamental. 2003. Dissertação (Mestrado em Educação) - Faculdade de Educação, Universidade Estadual de Campinas, Campinas, 2003.

CANTELLI, V. C. B. Um estudo psicogenético sobre as representações de escola em crianças e adolescentes. 2000. Dissertação (Mestrado em Educação) - Faculdade de Educação, Universidade Estadual de Campinas, Campinas, 2000.

CANTELLI, V.C.B. Procedimentos utilizados pelas famílias na educação econômica de seus filhos. 2009, Tese (Doutorado em Educação) - Faculdade de Educação, Universidade Estadual de Campinas, Campinas, 2009.

GODOY, E. A representação étnica por crianças pré-escolares: Um estudo de caso à luz da teoria piagetiana. Dissertação (Mestrado em Educação). Universidade Estadual de Campinas, Faculdade de Educação, 1996, 245 f.

PIRES, L.; ASSIS, O. Z. M. As representações das crianças sobre a noção de lucro: a construção do conhecimento social numa perspectiva construtivista. In: ASSIS, Mucio e MANTOVANI DE ASSIS, Orly. Anais do XXII Encontro Nacional de Professores do PROEPRE: Educação e Cidadania. Campinas: UNICAMP/FE/LPG, p. $471,2005$.

SARAVALI, E. G. As idéias das crianças sobre seus direitos: a construção do conhecimento social numa perspectiva piagetiana. Dissertação (mestrado em educação) - Faculdade de Educação, Universidade Estadual de Campinas, Campinas, 1999.

TORTELLA, J. C. B. Amizade no contexto escolar. Dissertação (Mestrado em Educação) - Faculdade de Educação, Universidade Estadual de Campinas, Campinas, 1996.

TORTELLA, J. C. B. A representação de amizade em díades de amigos e não amigos. Tese (Doutorado em Educação) - Faculdade de Educação, Universidade Estadual de Campinas, Campinas, 2001. 